\title{
Higher education as a visual practice: seeing through the virtual learning environment
}

Siân Bayne*

Higher and Community Education, The Moray House School of Education, The University of Edinburgh, Paterson's Land, Edinburgh, UK

As certain areas of practice in higher education shift online, the work of learners and teachers increasingly takes place within the domain of the image. The 'digital turn' we are experiencing, both in higher education and in the wider culture, accompanies an 'iconic turn' in which the logic of the image as it emerges on our screens has a growing influence over our working, thinking and learning practices. Visuality gains a new urgency as we move further into the digital age. This paper considers and critiques the form of visuality which increasingly mediates between pedagogy in higher education and digital space - the interface of the virtual learning environment or VLE. If the spatial organisation and visuality of the screen both represents and creates a value system and an ontology, what social and pedagogical practices does the VLE interface reflect, inform and inscribe? What meanings does it produce? What version of pedagogy does it 'make visible', and what alternatives does it blind us to?

Keywords: visuality; VLE; e-learning; image; interface; semiotics

\section{Introduction}

As the practices of higher education shift online, the work of learners, teachers and scholars increasingly takes place within the domain of the image. The 'digital turn' we are experiencing, both in higher education and in the wider culture, accompanies an 'iconic turn' in which the logic of the image as it emerges on our screens has a growing influence over our modes of meaning-making (Jewitt 2005; Kress 2003) - 'the knowledge society', as one group proclaims, 'has become a society of images' (Eikones 2005).

While digital culture and internet practices have contributed to what Mirzoeff calls 'the new urgency of the visual' (Mirzoeff 1999, 6), we can see these practices as emerging within a theoretical context which has long sought to articulate frameworks for analysing the image-saturation characteristic of Western society. The incursions of the digital add a mutable new dimension to decades of theorising of the visible and visual in culture, a scene which includes Barthes' 'Rhetoric of the image' (Barthes 1977), Berger's Ways of seeing (Berger 1972), Jay's 'scopic regime' (Jay 1988), Haraway's 'visual gluttony' (Haraway 1991), Lacan's gaze (Lacan 1977), Debord's Society of the spectacle (Debord 1977), Foucault's panopticism (Foucault 1979) and Virilio's 'vision machine' (Virilio 1994), to name only some of the most compelling. As Grosz reveals, cyberspace and visuality are each intimately bound up with the other:

*Email: sian.bayne@ed.ac.uk 
Cyberspace has become embodied in the screen not accidentally or contingently but because of the visualized nature of our culture and its prevailing pleasures. The technology predicated on an economy of watching has been pervasive for at least a century. (Grosz 2001, 22)

In an image-saturated culture, the need to conceptualise frameworks for describing and critiquing visuality is intense, in that image is never neutral or 'innocent', but rather works to enable particular ways of seeing and occlude others, situating and constituting subjects in specific ways (Rose 2001). As Foster puts it, visuality is about 'how we see, how we are able, allowed, or made to see, and how we see this seeing and the unseeing therein' (Foster 1988, ix). For Bartram, quoting Yi-Fu Tuan, 'Every new method or equipment refines and redefines, however slightly, the world for us ... The visual media, even as they open our eyes, blind us to other realities' (Bartram 2004).

Methodologies for describing and critiquing the image - emerging from the fields of art history, cultural studies, anthropology, sociology, linguistics, psychoanalysis and media studies - include content analysis, iconography, semiotics, social semiotics and visual ethnography. The term 'visual cultural studies' perhaps most usefully, and loosely, encompasses this methodological diversity, with its focus both on the way in which 'meaning and power are articulated within specific images', and how 'such images are produced and consumed within a wide range of social, economic and cultural contexts' (Lister and Wells 2001, 63).

While the discourses and methodologies of visual cultural studies and visual analysis have significantly informed educational theory and practice through the critical focus on visual literacy and 'multiliteracy' (for example Cope and Kalantzis 2000; Finan 2002; Kress 2003; Matthews 2005; New London Group 1996; Tyner 1998), there has been little critical analysis of the mode of visuality which increasingly dominates the mediation between pedagogy in higher education and the digital - the interface of the virtual learning environment or VLE.

If, as Johnson has claimed, the design of 'information space is the great symbolic achievement of our era' (Johnson 1999, 214), the mode of visuality represented in the graphical user interface offers a pressing need for critique. For it is the design of the interface which renders visible the vast unknowability of the 'microworld of electrons' (Poster 2001, 82) which constitute digital space and otherwise remain inconceivable.

How the complexity of digital space is represented in the interface is a creative act constitutive of a particular mode of visuality, a particular ontology and a particular series of ideological choices. It creates - and occludes - particular 'ways of seeing' information space, and both opens and closes off particular ways of being and acting online. In the context of higher education, the 'ways of seeing' constituted by the virtual learning environment are rarely subjected to the critique their increasing ubiquity demands $(83 \%$ of UK higher and further education institutions, and at least $75 \%$ of European universities currently use them in some form (Information World Review 2005; JISC 2003)).

While semiotic approaches are well-used in discussions of human-computer interface design (for example Condon, Perry, and O’ Keefel 2004; de Souza 2001; Liu, Crum, and Dines 1988; Salles, Baranauskas, and Bigonha 2001), this is an area of work generally informed by the discourses of instrumentality and accessibility, rather than by critique. Similarly, discussions of the virtual learning environment have in general focused around its instrumental functionality and 'affordances', rather than subjecting its interface to a visual analysis aimed at exploring how it represents and constructs informational and pedagogic space. 
While there are examples of semiotic analyses of web space (for example, Burnett and Marshall 2003; Orliaguet 1999), it is a methodology which is as yet little used in discussions of pedagogical web space (an exception is Selfe and Selfe 1994). As virtual learning environments (WebCT, Blackboard and their variants) become ubiquitous within higher education, the need to explore the implications of their visuality becomes urgent. If the spatial organisation and visuality of the screen both represents and creates a value system and an ontology, what social and pedagogical practices does the VLE interface reflect, inform and inscribe? What meanings does it produce? What version of pedagogy does it 'make visible', and what alternatives does it blind us to?

These questions form the focus of this paper, which attempts to apply a method of visual analysis to the virtual learning environment drawn from semiotic and social semiotic approaches to the reading of images. Such approaches attempt to develop frameworks for describing and critiquing the visual comparable with those we have for discussing the forms and modes of textual-linguistic meaning-making. Where semiotics is concerned with the study of the internal structure of signs and systems of signification, social semiotics informed by Halliday's systemic-functional linguistics (Halliday 1978) and by critical discourse analysis - extends this concern into an analysis of the socio-cultural processes by which signs emerge and circulate (Kress and van Leeuwen 1996).

To place a reasonable limit on the scope of my discussion, I will largely confine my analysis to one of the most dominant commercially developed virtual learning environments currently used in higher education globally - WebCT. I begin by considering the semiotics of some of the individual image elements present within the WebCT interface its logo and icons - and then move on to explore something of its underlying structure by drawing, in part, on what Kress and van Leeuwen call the 'compositional' function of the interface as image (Kress and van Leeuwen 1996). Throughout, my aim is to begin to develop insight into the ways the VLE constructs pedagogy and learning community, and the way in which it positions technologies for teaching and learning within the broader context of the academy in the digital age. I end the paper with an analysis of a 'web 2.0' alternative, looking at the way in which the pedagogical use of the wiki interface might offer us a different way of mediating and visually constituting learning and teaching online.

\section{'Safe' spaces: the icon}

Cousin (2005) has insightfully explored the conservatism inherent within the virtual learning environment - the nostalgia it represents for a stable, pre-digital world in its promised functionality as a neutral 'tool' working largely to 'enhance' already-existing teaching methods. The 'virtual classroom' metaphor, she argues, functions to 'pull up the drawbridge' on teachers and learners, to place them within a 'safe' space of enclosure directly analogous to the known physical and spatial reality of the materially present university (Cousin 2005).

The mode of visuality inscribed in the VLE interface, as I will argue here, functions to affirm this nostalgic vision of how teaching and learning is positioned in the information age. It is a vision which, while perhaps comforting in its promise of 'a stable transition' between media paradigms (Cousin 2005, 121), ultimately functions both to inhibit truly innovative pedagogical engagements with digital space, and to normalise a 'corporatised' construction of online higher education. 


\section{Logo}

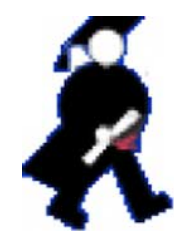

Cousin highlights the WebCT logo as indicative of the 'resonance' of VLEs with the 'old world' - 'we have the image of a little white, male professor complete with mortar board and gown, clutching the sturdy medium of paper. A set of images and vocabularies concerning VLEs trigger associations with a safe and known academic world.' (Cousin $2005,121-2)$

In semiotic terms, ${ }^{1}$ we might describe the logo as symbolic of the corporate entity WebCT in that the gowned figure (the signifier) has a purely conventional association with the signified (the software company). The image is also symbolic in that the gowned pedagogue signifies particular, historicised values of tradition, authority and didacticism. Yet we might also describe it as indexical in that we take the teacher figure as standing in a direct relationship to an alternative signified - the learning environment itself.

In this latter case, the signified values (tradition, authority and didacticism) are transferred to the virtual learning environment, coding it for stability and continuity in a way which masks the fundamental discontinuity involved in what is, by any standard, a radical media shift from conventional to digital modes of teaching and learning. The learning space is branded with a set of ideals associated with hierarchy, convention and continuity via the nostalgic imagery of 'the teacher'.

While the stance and swagger of the logo figure is distinctly suggestive of professorial authority and confidence, a possible alternative might be to see this as a student figure - a graduate. In this case, we are asked to transfer a slightly different set of signified values on to the virtual learning environment - those of the possibility of success within, and legitimation by, a system of higher education again characterised by continuity and tradition. Again, the effect is to limit and mask the radically new and potentially disruptive incursions of the digital.

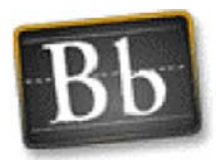

Blackboard

We see a similar pattern of signification with Blackboard, formerly WebCT's main commercial competitor and now its corporate acquirer. Here, the values signified by the blackboard itself - again, historicised ones of didacticism and tradition with the familiarity and continuity associated with an analogue writing technology - are complemented by the hint at an infantilising,

'back to basics' commitment to textual literacy, represented by spacer lines more often associated with early years handwriting practice than with higher education.

The transference of signification between the blackboard and Blackboard again functions to render the 'unknowability' of digital space knowable - as a learning space - in a way which is heavily coded for stability, authority and convention, and which limits the sense of the information space as a domain where new and potentially radically other pedagogical practices might emerge and be nurtured.

I now turn away from this brief discussion of the logo towards an analysis of the meanings encoded in the icons of the interface.

\section{Icon}

In one of the few pieces of work exploring the semiotics of the interface within the context of higher education, Selfe and Selfe (1994) highlight the way in which the computer 
'desktop' functions as a partial and 'interested version of reality' in which particular ideological positions are normalised. Their object of analysis is not the VLE, but rather the graphical user interface of the personal computer operating system. The 'corporate orientation' of this interface, they argue, is expressed through a visual dependence on the paraphernalia of the office environment (desktop, folder, files) within which the middleclass user feels comfortable. Such a visuality, however temporarily, interpellates or requires the user to identify with, and take up the subject position of, the dominant group. As educators, they suggest, we must develop a criticality in relation to the interface, recognising it - and teaching students to recognise it - as an interested and partial map of our culture' (Selfe and Selfe 1994, 495).

In discussing the 'iconology' of the VLE interface, I concur with this view in so far as I see the VLE as sharing something of the normative 'corporate orientation' identified by Selfe and Selfe with the desktop interface generally. Further than this, however, I also see VLE visuality as functioning to delimit the digital within analogue terms, to place constraints on the 'unknowability' of information space which, as they familiarise it, also deaden it to pedagogical uses capable of engagement with a genuinely digital culture. Digital pedagogy is in this way constructed by the VLE as existing purely within the terms of the analogue, the known, the face-to-face. Modelled on these terms, it can only ever exist as a shadow of its 'real', analogue other. The VLE, perhaps paradoxically, de-privileges the digital from the outset, rendering the online mode of learning itself as a hollow second best.

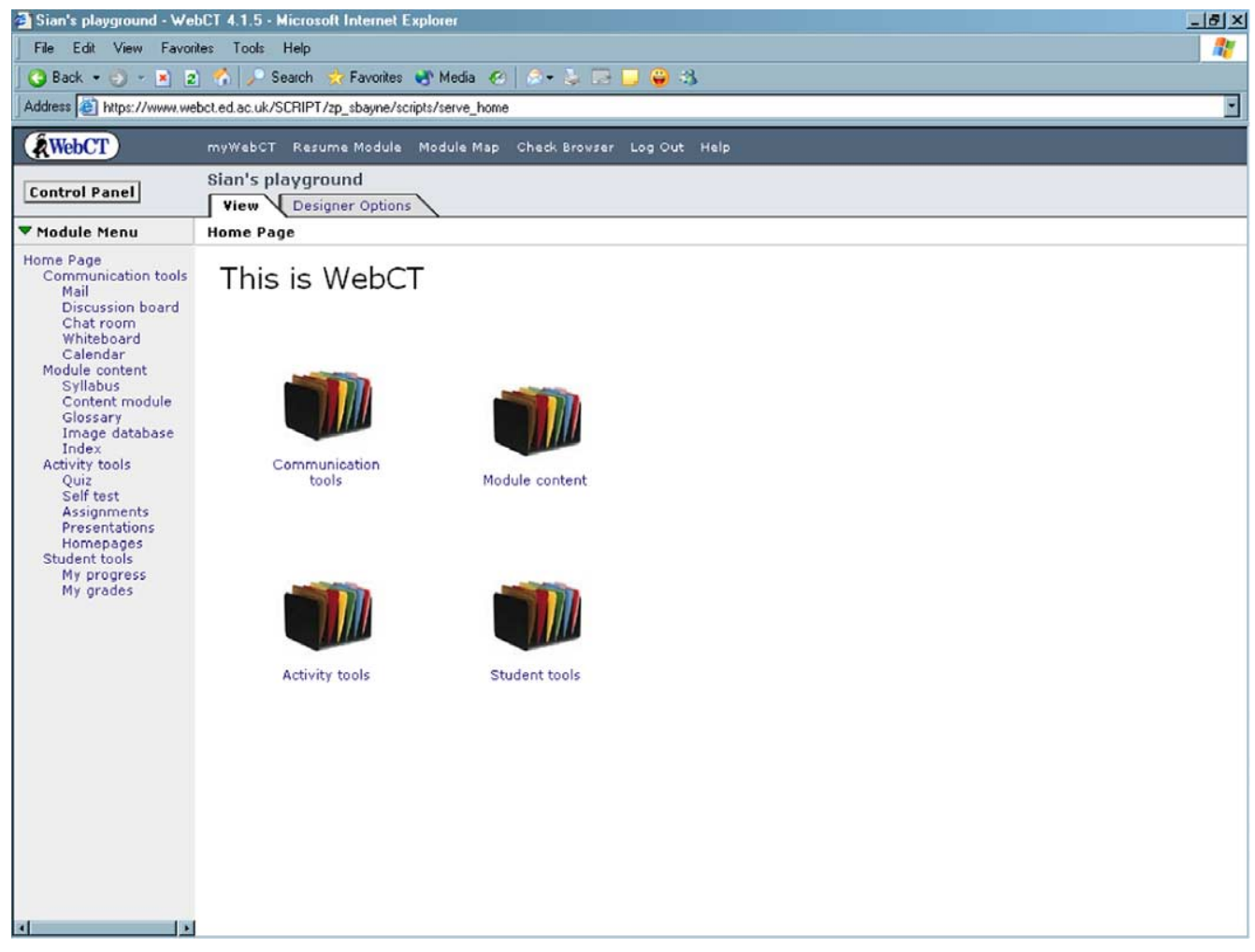

Figure 1. A simple WebCT home page. 
The screen shot shown in Figure 1 begins to demonstrate this, showing a simple WebCT home page consisting of icon links to four 'Organiser pages'. ${ }^{2}$ In creating a VLE space to critique, I have taken care to use only the default icon images provided with the software, and also to echo the terminology ('Course content', 'Content module', 'Student tools') used within the software itself. Clearly, the WebCT interface is mutable to the extent that the icons used, and their basic arrangement on the screen, may be customised by the teacher or designer who has the time, interest and technical know-how to do so. Similarly, institutional implementations of the software may differ slightly in terms of the positioning of logos, and the page templates and icon files made available. However, it is reasonable to argue that the default options of any piece of software bear a burden of assumption relating to how the software should be used and how meaning is to be constructed within that software environment - far from being value-free, they are default values, and therefore particularly open to critique. Therefore, while I might have chosen to use a 'real', highly customised WebCT course as the basis for my analysis - to do so would involve a form of reflection on a specific instance of practice which might be of significant value - I have instead attempted something more generalisable by reducing the interface to the 'rawness' of its default mode.

The learning space, and learning event, are visualised in this 'home page' in terms of a disaggregated series of functions, for which groups of 'tools' are provided. The 'toolbox' terminology is problematic from the outset, in that it casts the digital environment in instrumental mode, denying that the media shift forges an accompanying shift equally in teaching method and in the assumptions which drive such methods. As commentators from McLuhan on have affirmed, to see the technology as a 'tool' is to render ourselves blind to the changes wrought in us by technological shift. Existing teaching methods, as we know, cannot survive the shift into digital space intact, through the mediation of neutral 'tools' - nor should we desire them to. As Cousin has phrased it, such terminology 'promises a stable transition in an inherently unstable process of change from one media age to another, and promises no loss where there is always loss' (Cousin 2005, 121) (there are also many potential gains, some of which I will touch on in a later section).

The promise of stability suggested by the 'toolbox' metaphor is maintained in the representational, icon elements of the interface, which demonstrate both the 'corporatised' visual vocabulary identified as ideologically driven by Selfe and Selfe (1994) and the 'analogue' dependency highlighted above. Digital teaching and learning space is rendered visible via the paraphernalia of the distinctly pre-digital, corporate office environment. The folder image functions as an indexical sign much like the logos discussed above - the characteristics of the stable, graspable, familiar storage medium are implied for the online 'tool' in a shift of signification from the analogue to the digital which functions not only to occlude media difference but also to reduce the learning event to the status of 'filing'. Teaching and learning is here represented as an organisational rather than a generative issue.

Pursuing the environment down a level, we see a similar pattern of representation, with visual icons functioning in indexical mode to constitute elements of the digital learning space within the terms of a familiar - if corporatised - analogue culture. As with the WebCT logo already discussed, the imagery drawn on is often not merely pre-digital but almost pre-war in its historical positioning (see, for example, the images representing 'Index', 'Glossary', 'Quiz', 'Assignments'). These images are explicitly nostalgic in the way they attempt to draw connection between the mutable digital learning environment - in which so much relating to subject position, textuality, teaching method and communicative 


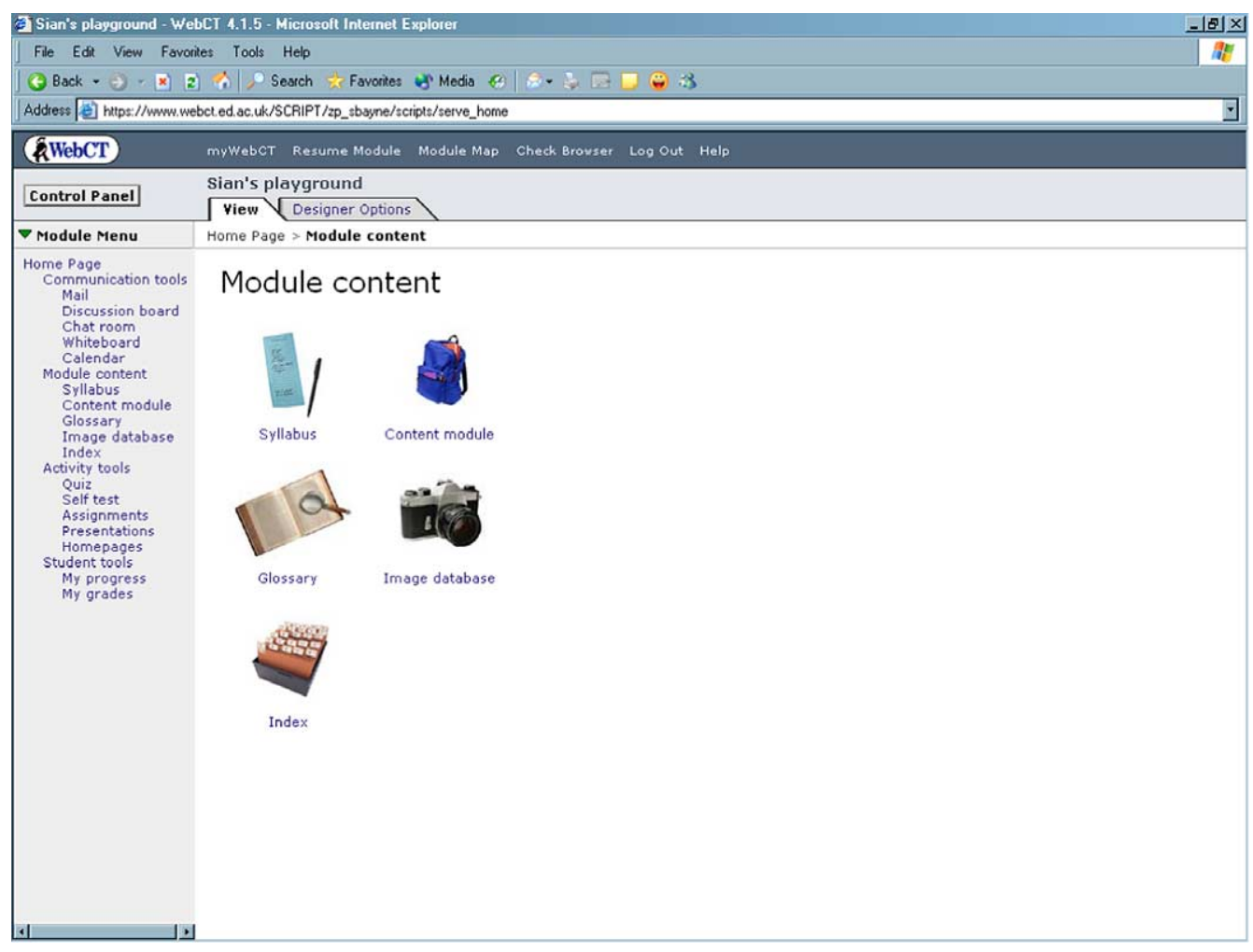

Figure 2. Imagery of nostalgia 1.

mode is new and 'up for grabs' - and an earlier era of relative technological stability (Figures 2 and 3).

Orliaguet, writing on the semiotics of the computer desktop, sees the dependence on iconic and indexical modes as extending throughout interface design, and as indicative of our nostalgic refusal of the specificity of the digital:

Indexical and iconic approaches ... try to reshape the material after its original image ... thereby denying any original aspect in digitality by tying it to the analog world. Of course, the whole process is in a sense very emotional, reminding more of the quest for paradise lost than a creation per se, as if to make us believe that all our belongings in the analog world survived the violence of digitisation. (Orliaguet 1999)

The mode of visuality which codes the VLE for pre-digital knowability and stability is, like all visual imagery, 'never innocent' (Rose 2001, 32) - the claim made for stability in the media age is, as Kress has revealed, itself ideological:

The real difference between times of seeming stability and times such as this is that now, we ... can neither pretend that there is stability nor demand it, other than as an ideological act. (Kress 2003, 11)

The 'digital turn' is an element of a technological shift which is caught up in far-reaching social, economic and cultural changes impacting on how we understand textuality (Bolter 2001; Kress 2003), subjectivity (Coyne 1999; Hayles 1999; Poster 2001), society (Castells 1996; Slevin 2000) and the place of higher education within it (Barnett 2000; Daniel 1998; Delanty 2001; Raschke 2002). Structuring the visuality of the digital learning environment 


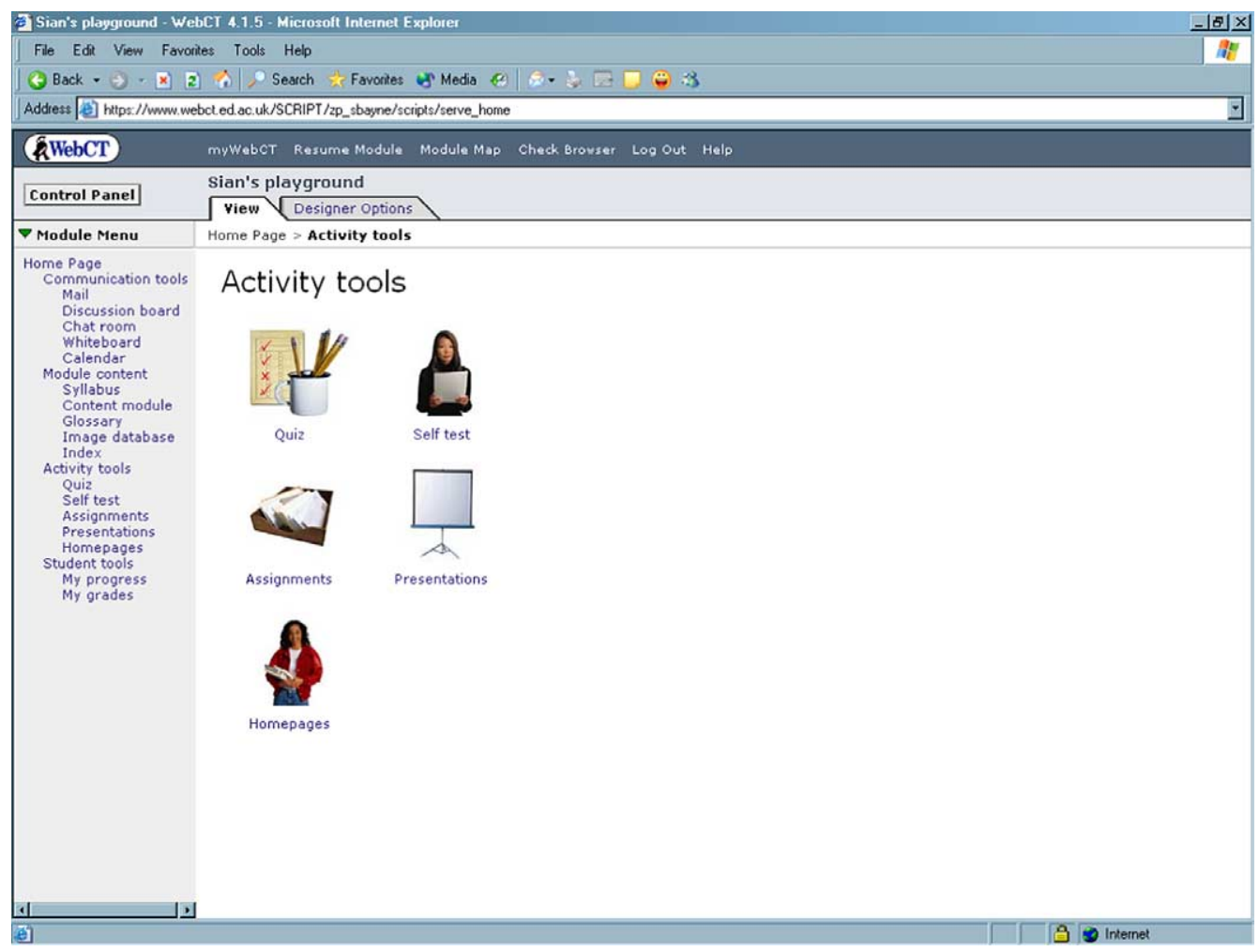

Figure 3. Imagery of nostalgia 2.

within the terms of nostalgia, continuity and the de-privileging of the digital mode itself, constitutes a refusal of these changes. It attempts an isolation of the everyday practices of learners and teachers from the shifting forces of digitisation, globalisation and 'postmodernisation', masking their effects and limiting the possibility for creative - and possibly resistant - pedagogical engagement with the new. In seeking to make us 'comfortable' with the digital it renders us - lotus-eater like - incapable of grappling with its real challenges. In the final section of this paper, I attempt to offer an alternative by discussing a learning environment which makes the attempt to engage creatively and actively with the characteristics specific to online digital space.

In discussing the visual form of the VLE icons I have, however, described nothing that cannot be changed and customised by an individual course designer with a certain, reasonably low, level of technical skill and confidence. I have touched on some of the more structural issues relating to the interface - in particular its disaggregation of teaching 'functions' and its instrumental logic - but a fuller account of its non-customisable aspects is needed. In attempting this I maintain my focus on the visuality of the medium - the VLE screen as image - and the way in which its compositional qualities constitute a particular 'visual reality' for online learning and teaching.

\section{Hierarchy and framing: the composition of the interface}

The organising logic of the WebCT interface is one of hierarchy, an articulation and visualisation of information space which restates the analogue dependence discussed 


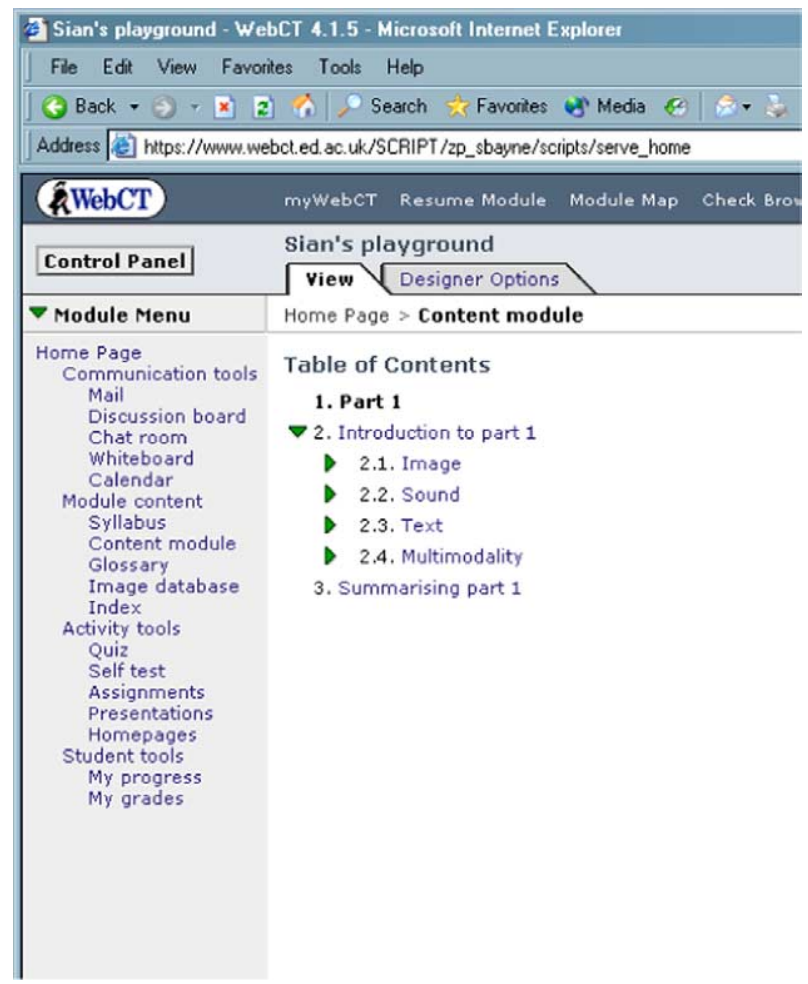

Figure 4. A hierarchical organising logic 1.

previously. The hierarchical orientation permeates this learning environment, from the semiotic connotations of its logo, to its hierarchy of users, to the hierarchically organised interface with its 'Content modules' (Figure 4), 'Module map' (Figure 5) and discussion board (Figure 6).

It could be argued that this hierarchical organisation merely reflects the file structure of the internet itself. However, I suggest that, much like its logos and icons, the structural linear-hierarchies of WebCT also function to render the interface familiar by relating it to a logic associated with the earlier writing technologies - in particular print - which have, historically, so informed our way of thinking and distributing knowledge within and beyond academia (Bolter 2001; Flusser 1992; McLuhan 1962; Ong 1982). If we accept that writing 'on the screen' is subject to a different logic - one more to do with the linkability of text, its mutability, manipulability and multilinearity - we can see the focus on linearity and hierarchy within WebCT as constituting yet another refusal of its own, digital, medium. To write hypertext within WebCT is to work against, rather than with the system - it is an environment driven by a conservatism which works to distance it visually and organisationally from its own form. There appears to be very little room for a 'digital sensibility' within WebCT, or within the everyday practices of the learners and teachers who use it.

A final aspect of the semiotics of the interface which I will briefly touch on here is that of 'framing', identified by Kress and van Leeuwen as one of three 'key elements' in the analysis of the composition of the image (Kress and van Leeuwen 1996, 214) - the first being 'information value' and the second 'salience'. Framing is the extent to which the 


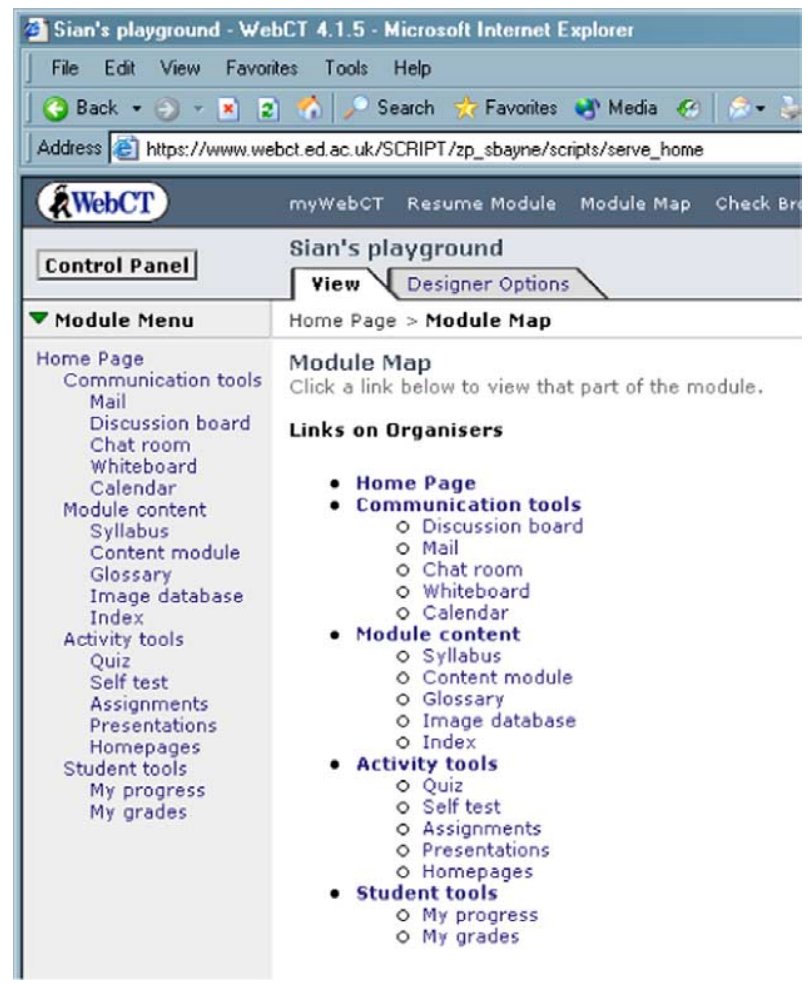

Figure 5. A hierarchical organising logic 2.

elements of an image are connected or disconnected, through the existence (or not) of literal framelines, empty space between elements or contrasts between colour and form (Jewitt and Oyama 2001). The semiotic potential of framing rests in its implications for the fragmentation or unity of the image elements:

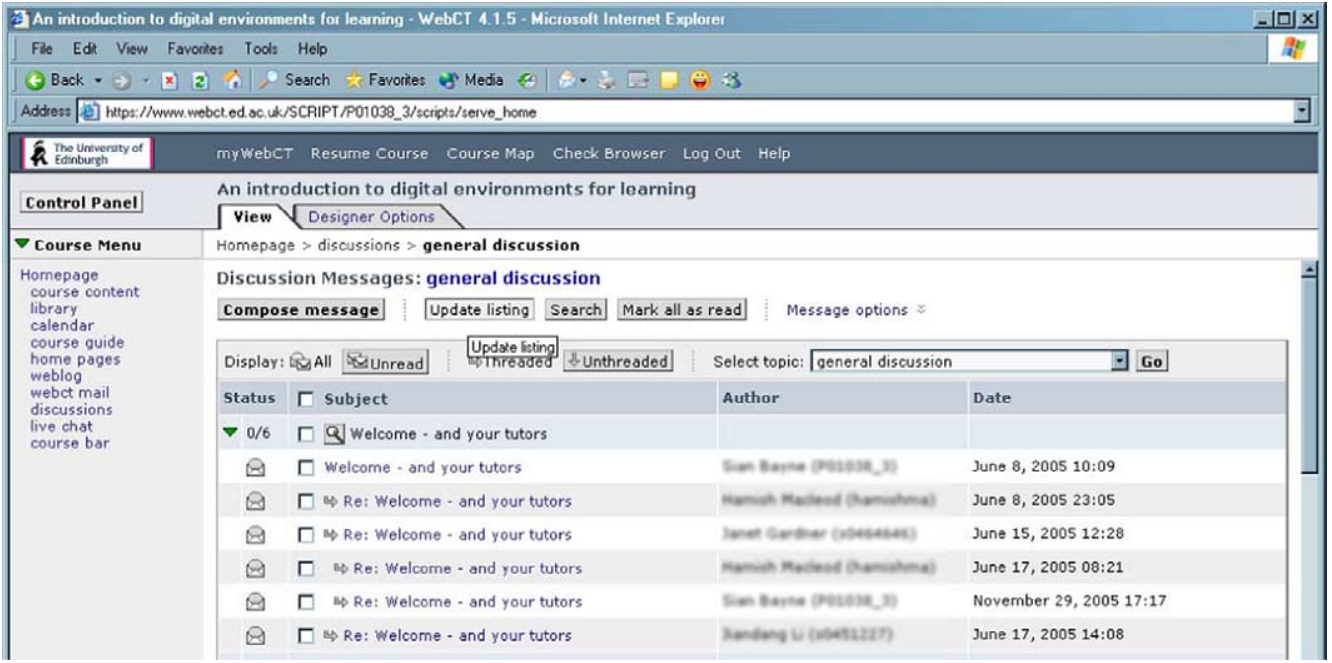

Figure 6. A hierarchical organising logic 3. 
The stronger the framing of an element, the more it is presented as a separate unit of information ... The absence of framing stresses group identity, its presence signifies individuality and differentiation... The more the elements of the spatial composition are connected, the more they are presented as one unit of information, as belonging together. (Kress and van Leeuwen 1996, 214-5)

In the context of the virtual learning environment, the screen shots show an extremely high degree of framing between the 'module' elements. The home page, for example, shows the 'Module content', and the communication, activity and 'student' 'tools' as being highly differentiated each from the other. Such differentiation suggests a strong and often inappropriate disaggregation of different learning and teaching 'functions'.

Here, again, metaphors generated from conventional face-to-face practice are imposed onto the digital medium. 'Module content' (roughly analogous to the lecture or the reading list) is differentiated from 'Communication tools' (roughly analogous to the seminar, tutorial or groupwork session) which are in turn differentiated from the 'Activity tools' (which are generally analogous to the course assessment). The value of the online mode rests partly in the way it can prompt us to re-conceptualise the learning space in a way that fundamentally problematises the differentiation of such 'functions'. Some of the most engaging digital pedagogies - I provide an example below - are those in which the activity on-screen constitutes equally, and synchronously, content, communication and assessment. These are teaching approaches which are 'born digital', and which require for their operation a mode of visuality, and textuality, which is fundamentally at odds with the disaggregated, heavily 'framed', hierarchical and print-oriented visual environment of WebCT.

\section{From walled garden to web 2.0: another way of visualising the virtual learning space}

In considering the 'ways of seeing' constituted by WebCT I have attempted to show how this particular articulation of the digital environment works to code the online learning space for stability, hierarchy, continuity and conservatism, 'masking' the disruptive incursions of the digital and rendering pedagogical information space visible within analogue terms. Such a space, and such a visuality, actively works against the ability of learners and teachers to craft pedagogies which engage creatively with the technologies of the digital age.

The 'web 2.0' applications currently growing in popularity and usage within higher education work to re-structure internet participation around the ideals of user contentgeneration and social networking. They also, perhaps, offer us opportunities for rethinking and re-crafting the visual modes by which we structure learning and teaching online. The closed-off, 'top-down' spaces of the traditional VLE are, in this new paradigm, replaced by the more volatile, open, linkable and possibly more truly 'digital' environments of the 'read/write' web (Alexander 2006).

I will end the paper, therefore, by discussing an example operating within this paradigm which seems to offer a more hopeful visual and textual form for learning and teaching in the media age. The example I use is a wiki environment called SnipSnap, shown here as it has been developed in an undergraduate English course at Bowdoin College in the States the 'Romantic Audience Project' (Romantic Audience Project 2003).

A wiki is a web-based document which allows a group of users easily to add and edit content using only their web browser. Content may consist of text, image or linkage, with most wiki software also allowing commentary postings and integrated discussion. A wiki depends on its users taking collective responsibility for the quality and nature of the wiki content - any user can amend, delete or extend any entry. Collectivity and shared content- 


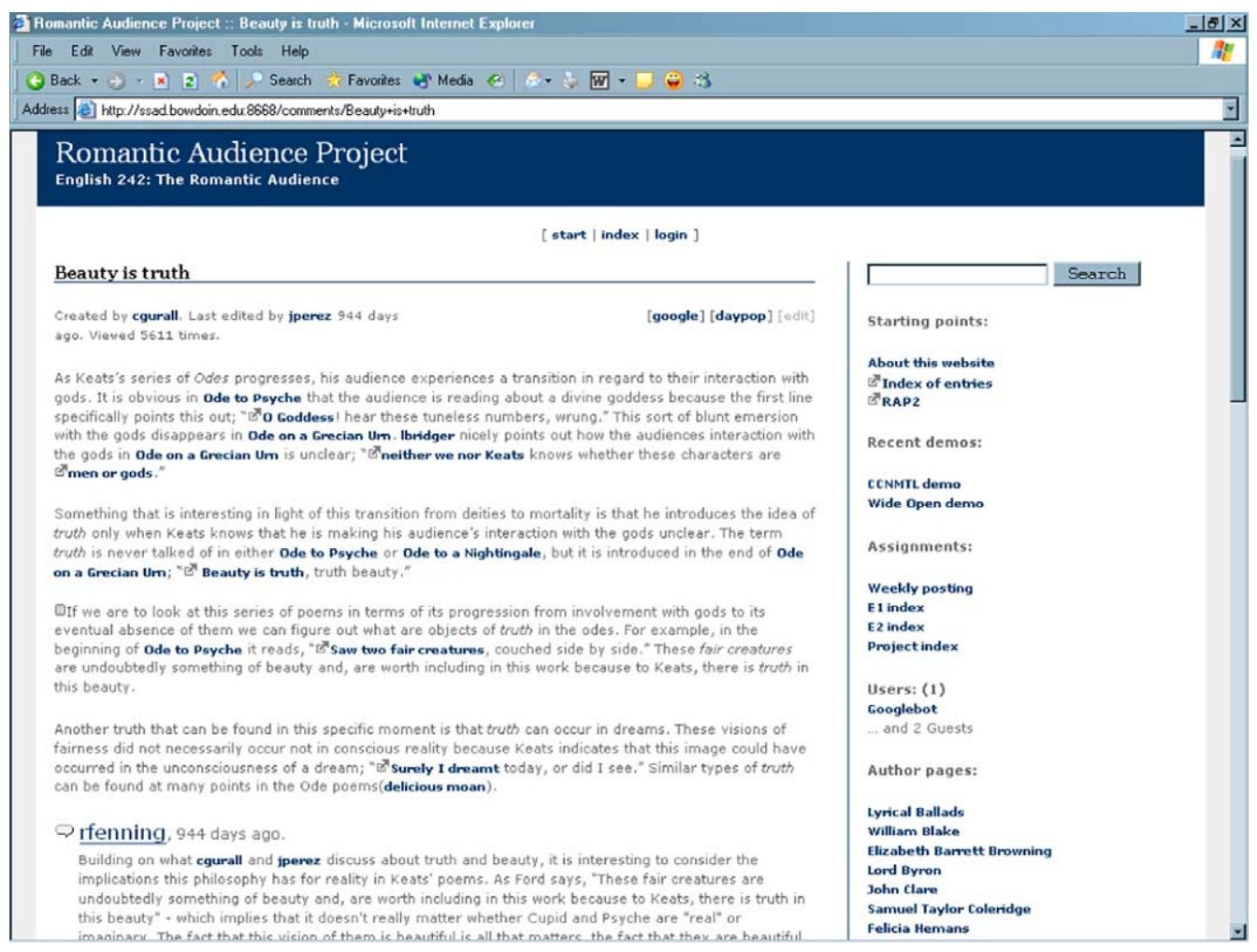

Figure 7. Communication as content in the wiki.

generation is its primary mode of operation. As the originators of the Romantic Audience Project (RAP) have reported:

This open-source software enabled modes of class activity unimaginable a few short years ago, yet quickly mastered by students used to interactive communication in their day-to-day lives. With a wiki, text, images, and multimedia could be put online by anyone in the class, no HTML required. Any word of any poem could be transformed into a link. Student comments could link to each other. Essays and projects could be openly critiqued, easily referenced, and efficiently archived. Rather than passively consuming web resources, the class actively and collectively authored in a digital environment, making its mark on the material it studied. (Phillipson and Hamilton 2003)

Figure 7, for example, shows how 'a student, jperez edits a comment on Keats's famous line posted by another student, cgurall, which in turn attracts a comment from a third student, rfenning' (Phillipson and Hamilton 2003). In this environment the distinction between content, communication and assessment is creatively undermined - the communicative form is itself the content of the course. Students on the Romantic Audience Project were required to make weekly postings to the wiki, which might consist in the posting of original insights into a particular text, or commentary on the posting of a fellow student. Two assignments were set, which themselves became part of the content of the wiki - as did the tutor's feedback on the assignment and any commentary other students on the course wished to add (assignment marks remained private). Unlimited linkage between text entries, commentary, external web sites, movies and images is enabled, within an ethos of multilinearity, linkability, openness and integration which contrasts strongly with the constraint and disaggregation of the WebCT interface (Figure 8). 


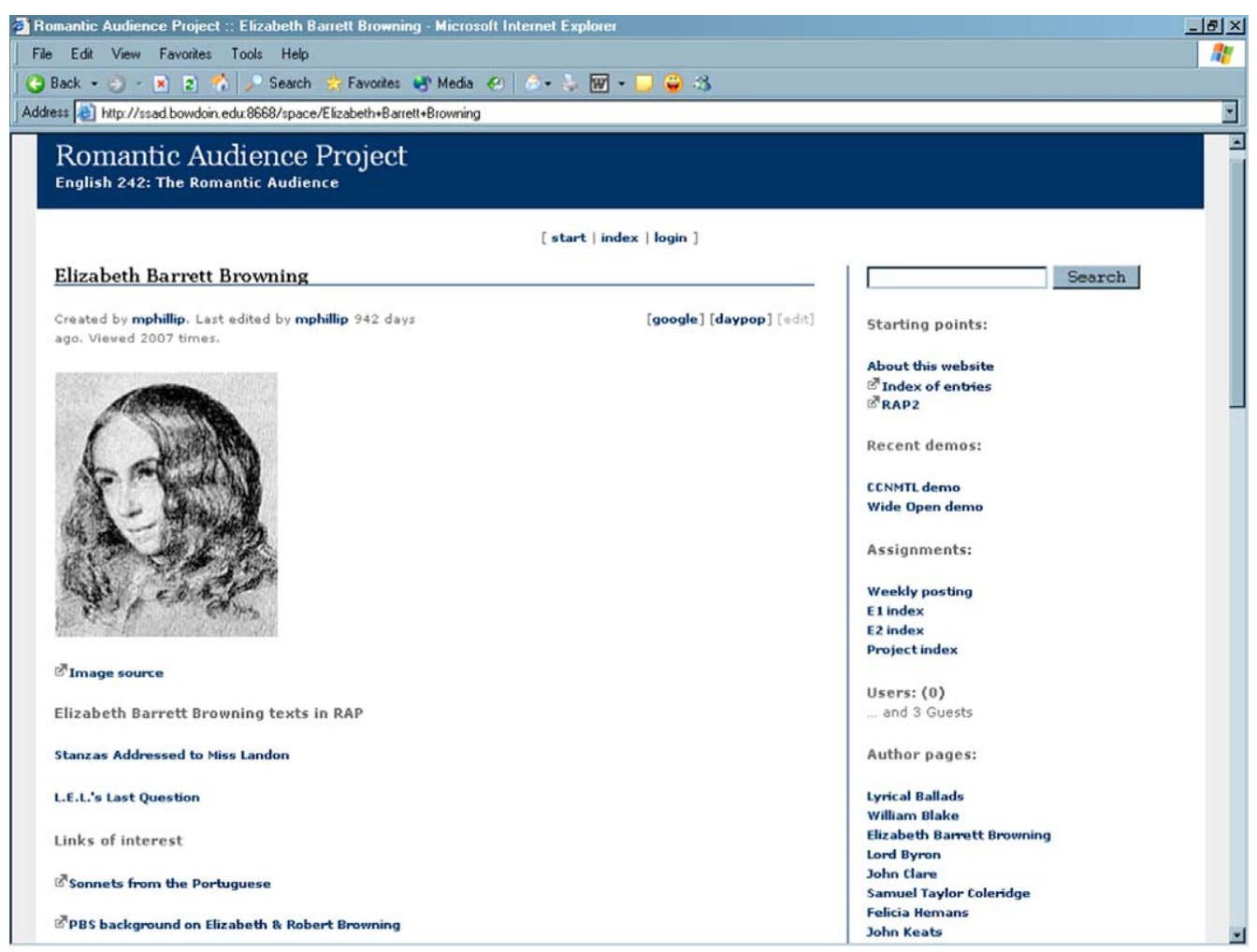

Figure 8. Linkage, multilinearity and openess in the wiki.

In terms of its visuality, this is a pared-down environment in which the indexical mode of signification operates, visually, only in the form of the hypertext link. Image fragments are freely uploadable, by anyone, but are not required to bear the semiotic burden of signifying particular learning tasks or 'tools' or to provide hooks to a more familiar, analogue world. Here, in a predominantly text-based and symbolic environment, distinctively digital ways of working are allowed to emerge on their own terms. The hierarchical logic which drives the visual semiotic and structural form of the WebCT interface is absent here, replaced by the multilinear logic of hypertext.

The wiki, it is true, can be an initially confusing and slightly uncomfortable environment to negotiate. Yet perhaps we can neither expect nor desire the shift of learning and teaching into virtual space (the 'violence of digitisation' (Orliaguet 1999)) to be merely comfortable. To seek comfort by turning to the commercial, out-of-the-box VLE can, as this paper attempts to demonstrate, constitute a refusal to confront the awkward and challenging incursions of the new media age. To do this leaves our learning and teaching practices subject to a regressive dependence on pre-digital metaphors, signs and practices which are neither sustainable nor, in the long term, desirable.

\section{Conclusion}

I have in this paper argued that WebCT functions, top-down, to impose a form of visuality subject to a range of compromises and conservative orientations. By contrast, aspects of wiki visuality and function can, perhaps, allow the learning space to 'become visible' 
through the collaborative work and active authorship of learners and teachers. I do not, however, promote the wiki - or any of the many other 'web 2.0' approaches to the learning environment - as a panacea, but rather suggest that it offers an alternative visuality, functioning as a learning space which is 'partial and interested' in very different, and arguably better, ways than those we experience through environments like WebCT.

More work is needed, not only in researching the place of 'web 2.0' in higher education, but in extending and refining our understanding of the role of the visual in mediating learning and teaching in the digital age. A new generation of open source learning environments may be beginning to challenge the corporate orthodoxies of WebCT/ Blackboard. However it is far from inevitable that such environments will challenge the conservative visual modes and metaphors which structure the earlier generation of VLEs. As teachers and learners in higher education we need to develop a nuanced awareness of the nature and power of these visual interfaces. Online learning space may be rendered visible in many ways - I have attempted here to show how awareness of that visuality can creatively, and critically, inform our pedagogical choices.

\section{Notes}

1. I use here Peirce's classification where (i) indexical represents a mode of signification in which the signifier is directly connected with the signified in some observable or inferable way without directly resembling it; (ii) the iconic mode is one in which signifier and signified directly resemble one another - a portrait, for example, and (iii) the symbolic mode is one in which the connection between signifier and signified is purely conventional, as is the case with language. The distinction is not absolute or mutually exclusive - a sign may represent a combination of all three modes dependent on its context of use (Peirce, C.S. 1935. Collected papers of Charles Sanders Peirce. Cambridge, MA: Harvard University Press.). I use the more accessible Saussurean terminology of 'signifier' (briefly, the form of a sign - a word or image) and 'signified' (the 'thing' or concept referred to) rather than Peirce's 'representamen' or 'sign' and 'object' (Sausurre, F.d. 1974. Course in general linguistics. London: Fontana.).

2. The software version referred to is the widely used WebCT Campus Edition 4.1. While the latest manifestations of WebCT/Blackboard, clustered under the term 'Blackboard Learning System', share many of the same driving assumptions and visual modes, they will require detailed consideration in their own right.

\section{References}

Alexander, B. 2006. Web 2.0: A new wave of innovation for teaching and learning? Educause Review 41, no. 2: $32-44$

Barnett, R. 2000. Realizing the university in an age of supercomplexity. Buckingham, UK: SRHE and Open University Press.

Barthes, R. 1977. Rhetoric of the image. Image-music-text. London: Fontana.

Bartram, R. 2004. Visuality, dromology and time compression: Paul Virilio's new ocularcentrism. Time and Society 13, no. 2/3: 285-300.

Bayne, S. 2004. Smoothness and striation in digital learning spaces. E-learning 1, no. 2: 302-16.

Berger, J. 1972. Ways of seeing. London: BBC and Penguin.

Bolter, J.D. 2001. Writing space: Computers, hypertext, and the remediation of print. 2 nd ed. Mahwah, NJ: Lawrence Erlbaum Associates.

Burnett, R., and P.D. Marshall. 2003. Look of the web. In Web theory, ed. R. Burnett and P.D. Marshall, 81-104. London: Routledge.

Castells, M. 1996. The information age: Economy, society and culture. Oxford: Blackwell.

Condon, C., M. Perry, and R. O'Keefe. 2004. Denotation and connotation in the human-computer interface: the 'Save As ...' command. Behaviour and Information Technology 23, no. 1: 21-31.

Cope, B., and M. Kalantzis eds. 2000. Multiliteracies: Literacy learning and the design of social future. South Yarra, Australia: Macmillan. 
Cousin, G. 2005. Learning from cyberspace. In Education in cyberspace, ed. R. Land and S. Bayne, 117-29. London: Routledge.

Coyne, R. 1999. Technoromanticism: Digital narrative, holism, and the romance of the real. Cambridge, MA: MIT Press.

Daniel, J. 1998. Mega-universities and knowledge media: Technology strategies for higher education. London: Kogan Page.

de Souza, C.S. 2001. Semiotic approaches to user interface design. Knowledge-Based Systems 14, no. 8: 415-18.

Debord, G. 1977. The society of the spectacle. Detroit, MI: Black and Red.

Delanty, G. 2001. Challenging knowledge: The university in the knowledge society. Buckingham, UK: Open University Press.

Deleuze, G., and F. Guattari. 1988. A thousand plateaus: Capitalism and schizophrenia. London: Continuum.

Eikones, P. 2005. Iconic criticism: The power and meaning of images. http://www.eikones.ch/ starte.html (accessed June 26, 2007).

Finan, N. 2002. Visual literacy in images used for medical education and health promotion. Journal of Audiovisual in Medicine 25, no. 1: 16-23.

Flusser, V. 1992. Die Schrift: hat schrieben zukunft? Gottingen, Germany: Edition Immatrix.

Foster, H. 1988. Vision and visuality. Seattle, WA: Bay Press.

Foucault, M. 1979. Discipline and punish: The birth of the prison. Harmondsworth, UK: Penguin.

Grosz, E. 2001. Architecture from the outside: Essays on virtual and real space. Cambridge, MA: MIT Press.

Halliday, M.A.K. 1978. Language as social semiotic. London: Edward Arnold.

Haraway, D. 1991. Simians, cyborgs and women: The reinvention of nature. London: Free Association Books.

Hayles, N.K. 1999. How we became posthuman: Virtual bodies in cybernetics, literature and informatics. Chicago, IL: University of Chicago Press.

Information World Review. 2005. E-learning inspires Euro universities. http://www.iwr.co.uk/ information-world-review/news/2083971/learning-inspires-euro-universities. (accessed June 26, 2007).

Jay, M. 1988. The scopic regimes of modernity. In Vision and visuality, ed. H. Forster, 3-28. Seattle, WA: Bay Press.

Jewitt, C. 2005. Multimodality, 'reading', and 'writing' for the 21st century. Discourse 26, no. 3: 315 31.

Jewitt, C., and R. Oyama. 2001. Visual meaning: A social semiotic approach. In Handbook of Visual Analysis. ed. T. van Leeuwen and C. Jewitt, 134-56. London: Sage.

JISC. 2003. Managed learning environment activity in further and higher education in the UK: executive summary. http://www.jisc.ac.uk/uploaded_documents/mle-study-exec-summary.doc. (accessed June 26, 2007).

Johnson, S.A. 1999. Interface culture: How new technology transforms the way we create and communicate. New York: Basic Books.

Kress, G. 2003. Literacy in the new media age. London: Routledge.

Kress, G., and T. van Leeuwen. 1996. Reading images: The grammar of visual design. London: Routledge.

Lacan, J. 1977. Ecrits: A selection. London: Tavistock.

Lister, M., and L. Wells. 2001. Seeing beyond belief: Cultural studies as an approach to analysing the visual. In Handbook of visual analysis, ed. T. van Leeuwen and C. Jewitt, 61-91. London: Sage.

Liu, K., G. Crum, and K. Dines. 1988. Design issues in a semiotic description of user responses to three interfaces. Behaviour and Information Technology 17, no. 3: 175-84.

Matthews, J. 2005. Visual culture and critical pedagogy in 'terrorist times'. Discourse 26, no. 2: 20324.

McLuhan, M. 1962. The Gutenberg galaxy. Toronto, ON: The University of Toronto Press.

Mirzoeff, N. 1999. An introduction to visual culture. London: Routledge.

New London Group. 1996. A pedagogy of multiliteracies: Designing social futures. Harvard Educational Review (Spring 1996) 66, no. 1: 60-92.

Ong, W.J. 1982. Orality and literacy: The technologizing of the word. New York: Methuen.

Orliaguet, J.-M. 1999. From UNIX to the desktop: A semiotic perspective on digital (r)evolution. http://www.ckk.chalmers.se/people/jmo/essays/unix_semiotics.html (accessed August 2, 2005). 
Peirce, C. S. 1935. Collected papers of Charles Sanders Peirce. Cambridge, MA: Harvard University Press.

Phillipson, M., and D. Hamilton. 2003. The Romantic Audience Project: A wiki experiment. http:// www.rc.umd.edu/pedagogies/commons/innovations/rap/index.htm (accessed June 26, 2007).

Poster, M. 2001a. The information subject. Amsterdam: G+B Arts International. 2001b. What's the matter with the internet? Minneapolis, MN: University of Minnesota Press.

Raschke, C.A. 2002. The digital revolution and the coming of the postmodern university. London: RoutledgeFalmer.

Romantic Audience Project. 2003. English 242: The Romantic audience. http://ssad.bowdoin. edu:8668/space/snipsnap-index (accessed June 26, 2007).

Rose, G. 2001. Visual methodologies. London: Sage.

Salles, J., M.C.C. Baranauskas, and R.S. Bigonha. 2001. Towards a communication model applied to the interface design process. Knowledge-Based Systems 14, no. 8: 455-59.

Sausurre, F. d. 1974. Course in general linguistics. London: Fontana.

Selfe, C., and R. Selfe. 1994. The politics of the interface: Power and its exercise in electronic contact zones. College Composition and Communication 45, no. 4: 480-504.

Slevin, J. 2000. The internet and society. Cambridge, MA: Polity Press.

Tyner, K. 1998. Literacy in a digital world: Teaching and learning in the age of information. Mahwah, NJ: Lawrence Erlbaum Associates.

Virilio, P. 1994. The vision machine. Bloomington, IN: Indiana University Press British Film Institute. 
Copyright of Teaching in Higher Education is the property of Routledge and its content may not be copied or emailed to multiple sites or posted to a listserv without the copyright holder's express written permission. However, users may print, download, or email articles for individual use. 